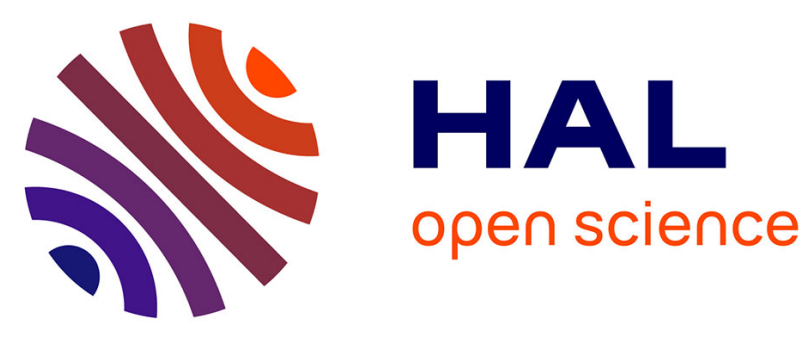

\title{
Erbium- and Magnesium-codoped Silica-Based Transparent Glass Ceramic Core Fiber Made by FCVD and Flash Vaporization
}

Jean-François Lupi, Michèle Ude, Stanislaw Trzesien, Borut Lenardič, Hervé Guillon, Wilfried Blanc, Bernard Dussardier

\section{To cite this version:}

Jean-François Lupi, Michèle Ude, Stanislaw Trzesien, Borut Lenardič, Hervé Guillon, et al.. Erbiumand Magnesium-codoped Silica-Based Transparent Glass Ceramic Core Fiber Made by FCVD and Flash Vaporization. 12th International Conference on Fiber Optics and Photonics (Photonics 2014, OSA), Indian Institute of Technology Kharagpur, and Optical Society of America, Dec 2014, Kharagpur, India. 10.1364/PHOTONICS.2014.T2B.6 . hal-01146579

\author{
HAL Id: hal-01146579 \\ https://hal.science/hal-01146579
}

Submitted on 28 Apr 2015

HAL is a multi-disciplinary open access archive for the deposit and dissemination of scientific research documents, whether they are published or not. The documents may come from teaching and research institutions in France or abroad, or from public or private research centers.
L'archive ouverte pluridisciplinaire HAL, est destinée au dépôt et à la diffusion de documents scientifiques de niveau recherche, publiés ou non, émanant des établissements d'enseignement et de recherche français ou étrangers, des laboratoires publics ou privés. 


\title{
Erbium- and Magnesium-codoped Silica-Based Transparent Glass Ceramic Core Fiber Made by FCVD and Flash Vaporization
}

\author{
Jean-François Lupi ${ }^{1}$, Michèle Ude ${ }^{1}$, Stanislaw Trzesien ${ }^{1}$, Borut Lenardič ${ }^{2}$, Hervé Guillon ${ }^{2}$, Wilfried Blanc ${ }^{1}$, \\ Bernard Dussardier ${ }^{1}$ \\ ${ }^{1}$ LPMC, Université Nice Sophia Antipolis, UMR CNRS 7336, Parc Valrose, 06108 Nice CEDEX 2, France \\ ${ }^{2}$ Optacore, Trpinceva ulica 39, 1000 Ljubljana, Slovenia \\ ${ }^{3}$ Kemstream, rue de la vieille poste, PIT de la Pompignane, Bât.T2, 34055 Montpellier CEDEX 1 \\ bernard.dussardier@unice.fr
}

\begin{abstract}
A fiber made by Furnace CVD was codoped with Erbium and Magnesium using a Flash Vaporization System for the first time. The fiber core is spontaneously formed as a Transparent Glass Ceramic (TGC). Due to the small nanoparticle size $(<50 \mathrm{~nm})$ and high volumetric density $\left(10^{20} \sim 10^{21} \mathrm{~m}^{-3}\right)$, the optical loss due to scattering is as low as $<0,6 \mathrm{~dB} / \mathrm{m}$. Erbium ions are highly concentrated within phase-separated nanoparticles. We study the absorption and emission properties of Erbium around $1.55 \mu \mathrm{m}$ in this TGC-core fiber.

OCIS codes: (060.2270) Fiber characterization; (060.2290) Fiber materials; (160.4236) Nanomaterials; (160.5690) Rareearth-doped materials; (160.6030) Silica.
\end{abstract}

\section{Introduction}

Developing of new rare-earth (RE)-doped optical fibers for power amplifiers and lasers requires continuous improvements in the fiber spectroscopic properties, besides the necessary increasing of device compacity and economical efficiency. However, some potential applications of RE-doped fibers suffer from limitations in terms of spectroscopic properties resulting from clustering of RE ions or inappropriate local RE-environment when they are inserted into silica. An interesting solution consists in using silica as a mechanical host and support of the fiber optical waveguide, and in embedding RE-ions within nanoparticles (NP) of appropriate composition and structure $[1,2]$. This embedding is critical to achieve some control over the spectroscopic properties of the fibers.

We have proposed an original route to obtain NP in fibers, that is based on the well known MCVD (Modified Chemical Vapor Deposition) process and the so-called solution doping method [3]. As silicate systems have a strong stable immiscibility when they contain divalent metal oxides, we take advantage of the thermal treatments inherent to this process to obtain NP through the phase separation mechanism. Through this route, NP are grown in-situ within the material when alkaline-earth ions $(\mathrm{Mg}, \mathrm{Ca}$ and $\mathrm{Sr}$ ) are incorporated into the fiber core [4,5,6]. In particular, the spectroscopic behaviour of erbium ions $\left(\mathrm{Er}^{3+}\right)$ depends on the concentration of the alkaline-earth elements [6].

The term Transparent Glass Ceramic (TGC) is adapted to bulk amorphous solids containing cristalline NP : for the sake of simplicity we apply this terminology also to the core of such fibers, although here the NP structure is not precisely determined. In order to increase the control of TGC formation, we study alternative processes to manufacture this type of fibers with an active TGC core with potential for optical amplification. Recently, alternative methods of doping with RE ions and modifying agents in silica during the MCVD process have been proposed and developed to meet the particular specifications for high power fiber lasers. Among these, those involving gas-phase doping (up to the reaction zone and deposition in the silica substrate tube) offer in principle a great flexibility $[7,8,9]$.

In this article we implement for the first time a Flash Vaporization System [9] to create a fiber with an active (i.e. amplifying) TGC core doped with $\mathrm{Er}^{3+}$ ions. The goal here is to evaluate the potential of this technique to create a TGC core and to embed $\mathrm{Er}^{3+}$ ions into NP. We present the principle of the FVS, the fiber preparation and we study the structure and composition of the fiber core, in conjunction with the absorption and emission properties of Erbium around $1.55 \mu \mathrm{m}$. These preliminary characterizations qualitatively allow us to discriminate between the contributions of the embedded $\mathrm{Er}^{3+}$ ions within NP, and from those dissolved in the surrounding glass.

\section{TGC fiber fabrication and characterization}

The preform was prepared on a FCVD lathe, a variant of MCVD using an inductively heated furnace as heat source instead of a gas torch. The reactives for synthesizing of the core layer were provided by a FVS (VapBox, 
Kemstream) with two injectors. Precursor liquids are sprayed into a heated chamber. The spray is immediately vaporized, and the reactive gas is carried by Helium to the reaction zone through a thermostatically controlled duct. The duct output end is travelling within the silica substrate tube synchronously with the furnace. The doped silica layer is synthesized by oxidation of the reactants and vitrification of the deposited soot during the pass. Our VapBox has two injectors. The first injector supplied a volatile solution of $\mathrm{Si}$ and Ge precursors (TEOS and TEOG, respectively) and the second injector provided a volatile solution of $\mathrm{Mg}$ and Er precursors (Erbium- and Magnesium-Tetramethylheptanedionate). Then the preform was conventionally collapsed and drawn into fiber. The core in the preform has a slightly milky appearance due to scattering of light by NP. The fiber core numerical aperture and diameter are 0.11 and $8.6 \mu \mathrm{m}$, respectively.

Preform and fiber samples were prepared for EDX compositional analysis and SEM imaging (backscattered electrons). The spatial resolution of EDX and SEM is in the order of $0.1 \sim 1 \mu \mathrm{m}$. The fiber absorption was obtained by multi-cutback transmission measurements and the fitting of longitudinal decay for each wavelength data point. The background loss was measured at $1.2 \mu \mathrm{m}$ on several samples $(3-5 \mathrm{~m} \mathrm{long})$ to less than $0.6 \mathrm{~dB} / \mathrm{m}$. At the $\mathrm{Er}^{3+}$ absorption peaks (at 978 and $1534 \mathrm{~nm}$ ), the absorption is $86 \mathrm{~dB} / \mathrm{m}$ and $182 \mathrm{~dB} / \mathrm{m}$, respectively. Hence, the average concentration of $\mathrm{Er}^{3+}$ ions in the core is $\sim 4.4 \times 10^{25} \mathrm{~m}^{-3}( \pm 10 \%)$ or $\sim 2100$ at.ppm. The room-temperature fluorescence under laser excitation at $980 \mathrm{~nm}$ was collected in a counter-propagating configuration, ensuring that any reabsorption effect was avoided (short sample, over-saturating pump power).

\section{Results and discussion}

Fig. 1 shows the SEM images of NP in (a) the preform and (b) in the fiber. First, one notices that the NP did not dissolve during the fiber-drawing stage. Their average size has diminished, though, from less than $\sim 50 \mathrm{~nm}$ downto less than $\sim 20 \mathrm{~nm}$ ). The interparticulate distance was also reduced; we estimate the volume density between $10^{20}$ and $10^{21} \mathrm{~m}^{-3}$ in the fiber.
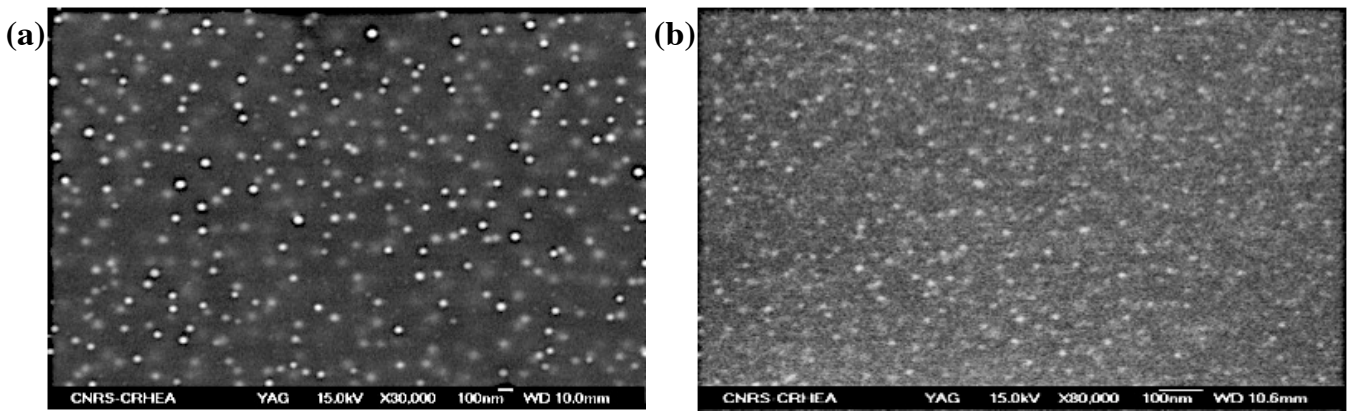

Fig. 1 : Backscattered electrons SEM images of (a) a polished preform and (b) a cleaved fiber. The white dots correspond to NP on the surface of samples. Scale bars: $100 \mathrm{~nm}$.

The EDX analysis (not shown) indicates that the elements Ge, $\mathrm{Mg}$ and Er are spread over the entire section of the core. The average concentration of $\mathrm{Er}$ and $\mathrm{Mg}$ are within $0.5-1.8 \mathrm{wt} \%$ and $0.2-0.5 \mathrm{wt} \%$, respectively. Er has a heterogeneous distribution that seems higher at NP locations. Mg has a rather low average concentration, that does not allow the see whether its distribution is also heterogeneous. However the resolution of EDX is greater than the size of a single NP or even one interpaticulate interval. This does not allow to conclude quantitatively on a possible partition (i.e. total incorporation) of Er and $\mathrm{Mg}$ within the phase separated NP, as we were able to observe in bigger NP grown using the solution doping method [5]. However there is a sharp rise in Er concentration in areas rich in NP compared to its value in areas with few or no NP. This would reveal an over-concentration of Er within the NP, well above the average concentration in the core ( 2100 at.ppm). Overconcentration of Er elements within NP would produce interaction clusters that cause efficient energy transfer among $\mathrm{Er}^{3+}$ ions and quenching of the nearinfrared fluorescence.

Fig. 2 shows the absorption and emission spectra of the fiber. They are compared with the spectra from characteristic Erbium-doped fibers, that are types I-germano-silicate, II-alumino-germano-silicate and III-aluminosilicate, respectively [10]. The stricking observation is that the absorption spectrum of the TGC-fiber compares well with that of a type-III fiber, whereas its emission spectrum resembles that of a type-I fiber.

This can be interpreted by considering two populations of $\mathrm{Er}^{3+}$ ions : the first is embedded within the NP, the second is dissolved in the surrounding matrix. Both absorption and emission spectra are each a superposition of the contributions of these two populations. In the case of an over-concentration of $\mathrm{Er}^{3+}$ ions within NP, then fluorescence quenching reduces or cancels the contribution of these ions in the emission spectrum (Fig. 2(b)): Then 
the latter is characteristic of the spectrum emitted by $\mathrm{Er}^{3+}$ ions in the germano-silicate host matrix. By contrast, the absorption spectrum (Fig 2 (a)) is not influenced by the fluorescence quenching: all $\mathrm{Er}^{3+}$ ions, including those embedded in NP, produce absorption spectra that are characteristic of their close surroundings. In Fig 2 (a), the absorption spectrum is very close to that from a Type-III fiber. In type-III fibers, aluminum element (Al) is in close vicinity of $\mathrm{Er}^{3+}$ ions; this modifies the spectroscopic properties of the rare-earth compared to that in pure or Gedoped silica. One expects that a similar phenomenon occurs in the TGC fiber, i.e. the $\mathrm{Er}^{3+}$ spectroscopy is under the influence of close-by, expectedly highly concentrated, $\mathrm{Mg}$ elements within the $\mathrm{NP}$, as we observed before [5,6]. Here, the absorption spectrum is so similar to that of type-III fiber that we hardly see any effects of the contribution of $\mathrm{Er}^{3+}$ ions in germano-silicate environment, except for a slight red-shifting of the absorption peak. This would indicate that the main contribution to the absorption spectrum is that from $\mathrm{Er}^{3+}$ ions located in NP. From this, we may conclude that at least the large majority of the $\mathrm{Er}^{3+}$ ions are embedded within NP, and that the NP composition and structure is very different from that of the surrounding germano-silicate matrix. This would give an interesting potential toward the controlling of the spectrocopic properties of RE ions in such fibers.

(a)

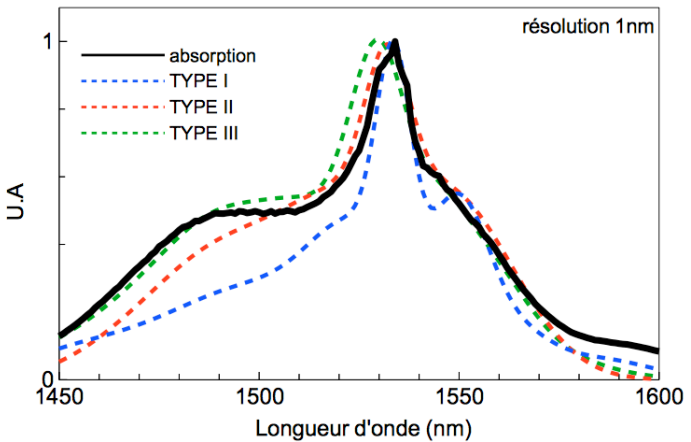

(b)

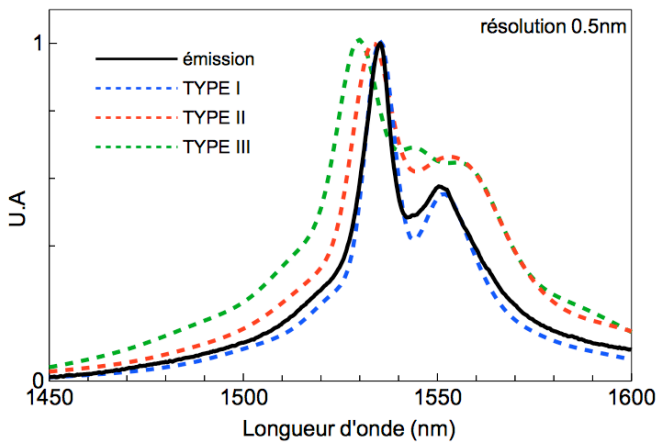

Fig. 2 : Er-Mg-codoped TGC fiber optical spectra at room temperature (black solid lines) : (a) absorption and (b) emission under 980-nm excitation. Dashed blue, red and green lines : spectra from Type-I, -II and -III fibers, respectively (computed from [10]).

\section{Conclusions and perspectives}

A fiber with an Erbium-doped Transparent Glass Ceramic fiber was made by FCVD and doped using a Flash Vaporization System for the first time. The preliminary characterizations indicate that a major fraction of the $\mathrm{Er}^{3+}$ ions are embeded within nanoparticles. Further characterizations are carried on to confirm our hypotheses. However in the fiber sample presented here, the local concentration of $\mathrm{Er}^{3+}$ ions in the NP causes significant quenching. This will be improved, for example by reducing the overall concentration of $\mathrm{Er}^{3+}$ ions, relative to the concentration of phase separators agents (here, $\mathrm{Mg})$. The good transparency of this TGC fiber $(<0.6 \mathrm{~dB} / \mathrm{m}$, acceptable for some applications) can be improved by process optimization (smaller NP, and greater volume density). The doping in gas phase by flash vaporization seems to have a good potential to produce such special amplifying fibers.

\section{References}

[1] B. N. Samson, P. A. Tick, and N. F. Borrelli, "Efficient neodymium-doped glass-ceramic fiber laser and amplifier," Opt. Lett. 26, 145-147

[2] C.I. Oppo, R. Corpino, P.C. Ricci, M.C. Paul, S. Das, M. Pal, S.K. Bhadra, S. Yoo, M.P. Kalita, A.J. Boyland, J.K. Sahu, P. Ghigna, F. d'Acapito, "Incorporation of $\mathrm{Yb}^{3+}$ ions in multicomponent phase-separated fibre glass preforms," Opt. Mat. 34 (4), 660-664 (2012).

[3] F. d' Acapito, C. Maurizio, M. C. Paul, T. S. Lee, W. Blanc, et B. Dussardier, "Role of CaO addition in the local order around Erbium in $\mathrm{SiO} 2-\mathrm{GeO} 2-\mathrm{P} 2 \mathrm{O} 5$ fiber preforms," Materials Science and Engineering: B 146, 167-170 (2008).

[4] W. Blanc, V. Mauroy, L. Nguyen, S.N. Bhaktha, P. Sebbah, B. P. Pal, B. Dussardier, "Fabrication of Rare Earth-Doped Transparent Glass Ceramic Optical Fibers by Modified Chemical Vapor Deposition," J. Am. Ceram. Soc. 94, 2315-2318 (2011).

[5] W. Blanc, C. Guillermier, B. Dussardier, "Composition of nanoparticles in optical fibers by Secondary Ion Mass Spectrometry," Opt. Mat. Exp. 2, 1504-1510 (2012).

[6] F. d' Acapito, W. Blanc and B. Dussardier, "Different $\mathrm{Er}^{3+}$ environments in Mg-based nanoparticle-doped optical fibre preforms," J. NonCryst. Sol. 401, 50-53 (2014).

[7] R. P. Tumminelli, B. C. McCollum, and E. Snitzer, "Fabrication of high-concentration rare-earth doped optical fibers using chelates," IEEE J. Light. Technol. 8, 1680-1683 (1990).

[8] A. J. Boyland, A. S. Webb, S. Yoo, F. H. Mountfort, M. P. Kalita, R. J. Standish, J. K. Sahu, D. J. Richardson and D. N. Payne, "Optical Fiber Fabrication Using Novel Gas-Phase Deposition Technique," IEEE J. Light. Technol. 29, 912-915 (2011).

[9] B. Lenardic, M. Kveder, H. Guillon and S. Bonnafous, "Fabrication of specialty optical fibers using flash vaporization method," in Proc. SPIE 7134, Passive Components and Fiber-based Devices V, M.-J. Li, P. Shum, I. H. White, and X. Wu, eds, Vol. $71341 \mathrm{~K}-11$ (2008).

[10] E. Desurvire, Erbium-Doped Fiber Amplifiers: Principles and Applications, 1st edition (Wiley-Interscience, 1994) pp. 250-254. 